\title{
A prestação obrigacional do anestesiologista como obrigação de resultado: sistematização e análise crítica dos argumentos a favor
}

\author{
The legal obligation of the anesthesiologist as a result \\ obligation: systematization and clinical analysis \\ of the fundamentals
}

\author{
Sergio Domingos Pittelli', Mário Flávio Seixas ${ }^{2}$
}

\begin{abstract}
Pittelli SD, Seixas MF. A prestação obrigacional do anestesiologista como obrigação de resultado: sistematização e análise crítica dos argumentos a favor. Saúde, Ética \& Justiça. 2012;17(1):21-5.

RESUMO: Os autores abordam e sistematizam os argumentos favoráveis à consignação de obrigação de resultados à obrigação jurídica do anestesiologista. São identificados os tipos de fundamentos e discutidas e exemplificadas as situações em que intervém a álea, considerando-se os momentos pré, intra e pós-anestésicos.
\end{abstract}

DESCRITORES: Anestesiologia; Responsabilidade civil; Doença iatrogênica.

1. Médico, mestre em ciências neurológicas pelo Departamento de Neurologia da FMUSP e doutor em ciências pelo Departamento de Medicina Legal da FMUSP. Advogado especializado na área da saúde.

2. Médico anestesiologista da Divisão de Neurocirurgia do Departamento de Psiquiatria da FMUSP. 
A exemplo da cirurgia plástica e da odontologia ${ }^{1,2}$, a prestação obrigacional do anestesiologista também é entendida por parte dos estudiosos do Direito como sendo de resultado.

Segundo pudemos registrar da literatura, há um único tipo de argumento que pretende sustentar essa posição. Exemplificamo-lo com Sant'Ana3:

Daí porque considero a anestesia uma obrigação de resultado, haja vista a responsabilidade do médico de anestesiar o paciente e, após, recuperá-lo, dentro de suas condições normais, devolvendo-lhe por completo todos os sentidos. Na medida em que aquele profissional examinou o paciente, no período pré-operatório, fez os exames necessários e o considerou apto para ser submetido àquele tipo de anestesia, obriga-se a recobrá-lo, de forma consistente e plena, se assim ele se encontrava, anteriormente ao ato anestésico.

O mesmo raciocínio é exposto em Matielo4:

Outra especialidade que merece destaque como geradora de obrigação de resultado é a anestesiologia, embora possa ser utilizada na prática tanto para situações de intervenções terapêuticas como noutras onde sobressai o aspecto embelezador. $\mathrm{O}$ anestesiologista tem, haja vista a tecnologia que envolve o ramo, condições de rigorosamente controlar a inconsciência do paciente, desde o seu estágio inicial até o mais profundo.

$\mathrm{Na}$ doutrina estrangeira, a personalidade mais notória que conhecemos é a de Santos Cifuentes (citado por Urrutia ${ }^{5}$ ), magistrado argentino de Tribunal Superior, segundo quem, as drogas anestésicas "bien utilizadas son inocuas para la salud general de las personas" e que em sua administração "no hay aleas graves".

Como se constata, a opinião baseia-se na concepção de que o ato anestésico consiste simplesmente em suprimir a consciência de uma pessoa (o que já não é tão simples como pretendido) e depois devolvê-la, como se se tratasse de ligar e desligar um aparelho, acionando um comutador.

Em texto anterior ${ }^{1}$ descrevemos a álea como qualidade de determinados processos cujos elementos não são de todo controláveis ou previsíveis, havendo, no seu transcurso, razoável grau de imponderabilidade "normal", sem que seja necessário apelar para fatos extras e/ou excepcionais, tal como no caso fortuito. Em outras palavras, a imponderabilidade (álea) é parte intrínseca do processo e verifica-se durante todo o seu devir.

Aduzimos agora que está intimamente associado ao conceito de álea o fato de que os eventos a ela sujeitos via de regra podem ser avaliados apenas em termos preditivos, seja quanto à possibilidade de ocorrência seja quanto às consequências, uma vez ocorrido. Por tal motivo são comuns na Medicina e ciências afins as escalas de avaliação de risco com os chamados "fatores preditores" de risco de ocorrência de determinados eventos. Os resultados, por sua vez, pelos mesmos motivos, são descritos invariavelmente como freqüências de incidência de cada uma das configurações possíveis.

Essa imprevisibilidade relativa de resultados finais e possibilidade de ocorrência de eventos adversos no transcorrer do procedimento faz com que o médico trabalhe sempre com um certo grau de incerteza, devendo tomar decisões baseadas em probabilidades e a princípio, pelo menos, provisórias.

A anestesiologia é eivada de situações tais como as transcritas acima, inclusive com o uso de fatores preditivos de riscos, tanto no pré- quanto no intra- e no pós-anestésico.

\section{Avaliação pré-anestésica}

Quando se fala em avaliação pré-anestésica vem imediatamente à mente a escala de risco anestésico da American Society of Anesthesiology (ASA) e os inúmeros algoritmos criados com a finalidade de medir o risco de determinadas complicações.

Segundo Novaes (6), a escala preditiva ASA, introduzida em 1941, prevê risco de mortalidade que varia de 0,06 a $0,08 \%$ no nível ASA $1(\mathrm{P} 1)$ até 9,4 a $51 \%$ para o nível ASA 5 (P5).

Esse autor divide os fatores prognósticos em três níveis: maiores, intermediários e menores, classificando entre eles inúmeros quadros cardíacos/coronários, diabetes mellitus, insuficiência renal crônica, história prévia de Infarto Agudo do Miocárdio (IAM), história prévia de Acidente Vascular Cerebral (AVC), Eletrocardiograma (ECG) anormal e hipertensão arterial não controlada, entre outros, além do porte da cirurgia.

Apenas a título de ilustração, segundo o autor citado, a morte é quatro vezes mais frequente no primeiro dia de pós-operatório, independentemente da idade, sendo que mais da metade das mortes ocorrem por lesão cardíaca. Além disso, o paciente que sobrevive a um infarto do miocárdio pós-operatório, tem duas vezes mais chance de falecer nos dois anos seguintes à cirurgia do que o paciente não complicado. Daí concluir esse autor que o principal foco da avaliação anestesiológica pré-operatória deve ser cardiológico. Refere inúmeros algoritmos e índices "que tentam prever a probabilidade de complicações cardíacas no 
período perioperatório", citando como o mais preciso e fácil de memorizar o RCRI (Revised Cardiac Risk Index). Em função da avaliação assim realizada, propõe oito possíveis decisões a respeito da cirurgia: cancelá-la, modificar o procedimento cirúrgico proposto, adiar o procedimento para tratamento de quadro instável, modificar a monitorização intraoperatória, modificar o tratamento medicamentoso perioperatório, citando a possibilidade de eventual introdução de beta-bloqueadores, estatinas e alfa-2 agonistas, modificar a monitorização pós-operatória e, por último, realizar cirurgia de revascularização miocárdica profilática.

Numa ordem de fatos completamente diversa, mas mantendo a mesma natureza de eventos caracterizados pela álea, temos a dificuldade de intubação e manutenção de via aérea pérvia ("Via Aérea Difícil" - VAD).

Melhado (7) divide os elementos relacionados à dificuldade em dois grupos: presença de doenças com comprometimento da via aérea (VA) e aspectos anatômicos e funcionais.

Cita entre os primeiros, como fatores a dificultar o acesso e manutenção de VA pérvia, patologias congênitas (apresentando inúmeros exemplos), trauma, patologias endócrinas (obesidade, diabete mellitus, acromegalia, síndrome de Cushing), processos inflamatórios (espondilite anquilosante, artrite reumatoide), condições fisiológicas (gestação), tumores (em VA alta e baixa), infecção (epiglotite, abscessos, difteria, bronquite e pneumonia), corpo estranho, história de radioterapia ou cirurgia de cabeça e pescoço e história de ronco e apneia do sono.

Entre os segundos, lista onze fatores anatômicos a serem avaliados, tais como comprimento dos incisivos superiores e relação entre incisivos maxilares e mandibulares.

Em face destes elementos e circunstâncias, foram criados "protocolos de intubação difícil"8,13 que são, em última análise, algoritmos nos quais, frente à possível ocorrência de determinado evento, preconiza-se determinada forma de conduta.

\section{Fase intra-anestésica}

Bloom e Baker ${ }^{10}$ classificam em 20 grupos as complicações que podem ocorrer durante o ato anestésico.

A seguir citamos, com base nesses autores, a título de exemplo, alguns eventos possíveis mas preditíveis apenas estatisticamente, e dependentes de práticas anestésicas regulares. Alguns, mas nem todos, dependentes da vigência de quadros clínico/metabólicos alterados.
Hipotensão arterial. Decorrente de depressão miocárdica, a qual por sua vez é efeito encontrável na imensa maioria dos anestésicos, do uso de antagonistas beta-adrenérgicos, de bloqueadores dos canais de cálcio e lidocaína (também depressores do miocárdio), de disfunção cardíaca aguda consequente a IAM ou isquemia do miocárdio, de hipocalcemia, de acidose ou alcalose grave, de hipotermia, cor pulmonale e reflexos vagais, lembrando que este último costuma ser decorrente de manobras praticadas pelo cirurgião (ou seja, nem sequer é consequência de ação do anestesiologista), geralmente por tração em estruturas inervadas pelo vago. A hipotensão pode ainda ser consequência de diminuição da resistência vascular sistêmica (RVS) decorrente, por sua vez, da administração de um número enorme de drogas de uso regular em anestesia (isoflurano, opiáceos, propofol, benzodiazepínicos, etc.), de retorno venoso inadequado, causados entre outros, por compressão da veia cava devida a manobra cirúrgica, útero grávido ou aumento da pressão intra-abdominal durante laparoscopia. Citam-se ainda as arritmias como causa de hipotensão.

Hipertensão arterial. Pode ser devida simplesmente à presença de doença pré-existente (hipertensão essencial, feocromocitoma), ou, em se tratando de atividades intraoperatórias, pinçamento da aorta (manobra cirúrgica) e interações medicamentosas.

Arritmias. Devidas a cardiopatia, administração de drogas regularmente utilizadas em anestesia (succinilcolina, anticolinesterase, bloqueadores beta-adrenérgicos, etc.) e aumento do tônus vagal (manobra cirúrgica).

A lista é enorme e evidentemente não é o caso de apresentá-la por completo. Citamos apenas como outras complicações em cujas causas encontramse eventos com as características acima apontadas (manobras anestésicas regulares e drogas de uso regular em anestesia) as seguintes: hipoxemia, hipotermia, hipercarbia, hipertermia (valendo citar aqui uma causa particular: a hipertermia maligna), diaforese (sudorese), broncoespasmo, pneumotórax, isquemia miocárdica, embolia pulmonar e reações anafiláticas e anafilactóides.

\section{Fase pós-anestésica}

Também a fase pós-anestésica, tanto imediata quanto tardia, apresenta situações de risco e imprevisibilidade natural e intrínseca aos procedimentos regulares do anestesiologista.

Kumar e George ${ }^{11}$ afirmam que cerca de 5\% dos pacientes admitidos em Sala de Recuperação pós-anestésica (SRPA) apresentam complicações 
de gravidade no mínimo moderada e classificamnas nas seguintes categorias: complicações ventilatórias e das vias respiratórias, perturbações hemodinâmicas, náuseas e vômitos pós-operatórios, complicações renais e comprometimento neurológico.

A seguir serão citadas apenas umas poucas complicações de cada categoria, tão somente a título de exemplo. É relevante registrar que todas elas podem ocorrer como decorrência de manobras regulares do anestesiologista e não apenas como alguma forma de erro na conduta do médico.

Para exemplificar, sempre segundo os autores em referência, a anestesia geral está associada à inibição do estímulo ventilatório hipóxico e hipercapneico e à redução da capacidade residual funcional (CRF) pulmonar. Essas alterações podem persistir por um período variável, após o final dos procedimentos anestésicos, e predispor a hipoventilação e hipoxemia. O interessante, e de suma significância para os propósitos deste texto, é que não há consenso na literatura sobre a administração profilática de oxigênio (contrariamente ao que pode parecer, à primeira vista, aos olhos do leigo), pois essa medida pode mascarar e retardar a detecção da hipoventilação por oximetria de pulso. Além de constituir exemplo de complicação que pode decorrer exclusivamente de procedimentos anestesiológicos regulares, mostra situação na qual o médico é obrigado a pesar prós e contras e decidir segundo critérios de probabilidade, jamais de certeza.

Atelectasias "espontâneas" podem decorrer da diminuição da CRF, com aumento do shunt intrapulmonar. Tais fenômenos são potencializados por obesidade e procedimentos torácicos ou abdominais altos. A recuperação inadequada dos reflexos e do tônus das vias aéreas pode levar a obstrução respiratória alta sendo mais frequentes em pacientes obesos ou com história de apneia obstrutiva do sono. Como último exemplo, cita-se o broncoespasmo, que pode ocorrer "espontaneamente", principalmente em crianças e pacientes adultos com doença pulmonar obstrutiva crônica (DPOC). É citada como uma das causas do broncoespasmo a simples manipulação das vias aéreas durante as manobras de intubação.

Dentre as alterações hemodinâmicas cita-se a hipotensão que pode decorrer de diminuição do retorno venoso, por sua vez consequente ao uso de ventilação com pressão positiva ou ainda hiperinsuflação pulmonar dinâmica com consequente pressão expiratória final positiva intrínseca (auto-PEEP), todos procedimentos anestesiológicos regulares.

A hipotensão pode ainda ser causada por vasodilatação consequente ao uso de anestesia neuraxial (intra-raquídea e peridural) e agentes inalatórios bem como por reações transfusionais e anafilaxia, os primeiros constituídos por procedimentos anestesiológicos regulares e os últimos, eventos idiossincráticos imprevisíveis.

Além de poder ocorrer como consequência de IAM ou isquemia intra-operatória, a diminuição do débito cardíaco pode também decorrer do simples uso de fármacos inotrópicos negativos, tais como anestésicos, bloqueadores beta-adrenérgicos, bloqueadores dos canais de cálcio e antiarrítmicos, todas drogas de uso regular em anestesiologia.

Mais uma vez restringiremos os exemplos à lista acima, por questões de economia de espaço.

Enfatizamos mais uma vez, ao concluir, que a lista de complicações acima delineada é decorrente de procedimentos anestesiológicos regulares, seja o uso de fármacos, sejam procedimentos propriamente ditos tais como intubação, punção venosa superficial e profunda, punção do canal raquiano, etc.

Além disso, há que considerar todos os elementos decorrentes de eventuais moléstias associadas, além, obviamente, da moléstia que ocasionou a cirurgia, todas fatores de imponderabilidade. Por último, há que considerar elementos ligados ao andamento da própria cirurgia (sangramentos, alterações hemodinâmicas ou ventilatórias devidas a manobras cirúrgicas, etc.)

\section{CONCLUSÃO}

Pelo exposto, constata-se que o ato anestésico é pleno de álea, contrariamente ao afirmado por Sant'Ana ${ }^{3}$ e Matielo'.

Se assim não fosse, não haveria qualquer problema no fato de o anestesiologista praticar mais de um ato simultâneo ou ausentar-se da sala. Se não pode fazê-lo é exatamente em função do risco e do acaso, dos eventos inesperados que podem acontecer em sua ausência.

Chega a ser até irônico um dos autores acima citados $^{3}$ apontar o exame pré-anestésico como fundamento da obrigação de resultado, quando é sabido que o próprio exame clínico é eivado de medidas interpretativas e o próprio ato de fazer diagnóstico (implícito no exame) é aceito sem ressalvas como obrigação de meio.

Ressalta-se também a ingenuidade da afirmação de Santos Cifuentes (citado por Urrutia ${ }^{5}$ ) relativa à inocuidade das drogas anestésicas.

Concluímos que a única "obrigação de resultado" do anestesiologista é não praticar dois atos anestésicos simultâneos e não abandonar a sala cirúrgica, mesmo assim, ressalvando-se situações de força maior. 
Pittelli SD, Seixas MF. A prestação obrigacional do anestesiologista como obrigação de resultado.

Pittelli SD, Seixas MF. The legal obligation of the anesthesiologist as a result obligation: systematization and clinical analysis of the fundamentals. Saúde, Ética \& Justiça. 2012;17(1):21-5.

ABSTRACT: The authors address and schematize the arguments in favor of the assigning of the result nature to the anesthesiologist's legal obligation. The fundaments are identified and discussed as well as exemplified the situations in which the alea intervenes. The pre, intra and post-anesthetic phases are considered.

KEYWORDS: Anesthesiology; Damage liability; latrogenic disease.

\section{REFERÊNCIAS}

1. Pittelli SD. A prestação obrigacional do cirurgião plástico como obrigação de resultado: sistematização e análise crítica dos argumentos. Saúde Ética Justiça. 2011;16(2):93-102.

2. Pittelli SD, Motta MV. A prestação obrigacional do dentista como obrigação de resultado: sistematização e análise crítica dos argumentos [no prelo].

3. Sant'ana GC. Responsabilidade civil dos médicos anestesistas. In: Bittar CA, coordenador. Responsabilidade civil médica, odontológica e hospitalar. São Paulo: Saraiva; 1991.

4. Matielo FZ. Responsabilidade civil do médico. Porto Alegre: Sagra Luzzato; 1998.

5. Urrutia AR, et al. Responsabilidad médico-legal de los anestesistas. Buenos Aires: La Rocca; 2005. p.8999.

6. Novaes MV. Avaliação e preparo pré-operatório: classificação do estado físico. In: Cavalcanti IL, Cantinho $\mathrm{FAF}$, Assad A, editores. Medicina perioperatória. Rio de Janeiro: SAERJ; 2006.
7. Melhado VB. Avaliação da via aérea difícil. In: Cavalcanti IL, Cantinho FAF, Assad A, editores. Medicina perioperatória. Rio de Janeiro: SAERJ; 2006.

8. Sociedade Brasileira de Anestesiologia. Intubação traqueal difícil - Projeto Diretrizes AMB - CFM [citado em 22 abr. 2012]. Disponível em: http://www.projetodiretrizes.org.br/projeto_diretrizes/070.pdf.

9. UNIFESP. Protocolo de via aérea difícil [citado em 22 abr. 2012]. Disponível em: http://www.unifesp.br/dcir/ anestesia/via_aerea.pdf.

10. Bloom JD, Baker K. Problemas Durante a Anestesia In: Levine WC, Allain RM, editor Manual de anestesiologia clínica - procedimentos do Massachussets General Hospital. 8a ed. Rio de Janeiro: Guanabara Koogan; 2012.

11. Kumar A, George EE. A sala de recuperação pósanestesia. In: Levine WC, Allain RM, editor sênior. Manual de anestesiologia clínica - procedimentos do Massachussets General Hospital. 8 ${ }^{\underline{a}}$ ed. Rio de Janeiro: Guanabara Koogan; 2012. 